\title{
Derivational Morphology in the German Mental Lexicon: A Dual Mechanism Account
}

\author{
Harald Clahsen \\ University of Essex \\ Ingrid Sonnenstuhl \\ University of Düsseldorf \\ James P. Blevins \\ University of Cambridge
}

Revised Version: February 2002

Corresponding Author:

Harald Clahsen

Department of Linguistics

University of Essex

Colchester, C04 3SQ, UK

Tel: +44/1206/87-2228

Fax: +44/1206/87-2085

email: harald@essex.ac.uk 
Abstract

The Dual Mechanism Model posits two different cognitive mechanisms for morphologically complex word forms: decomposition of regulars into stems and exponents, and full-form storage for irregulars. Most of the research in this framework has focused on contrasts between productive and non-productive inflection. In this paper, we extend the model to derivational morphology. Our studies indicate that productive derivation shows affinities with both productive and non-productive inflection. We argue that these results support the linguistic distinction between derivation and inflection, particularly as it is represented in realization-based models of morphology. 


\section{Introduction}

Proponents of the Dual Mechanism Model have claimed that the mental grammar has a dual structure with two distinct representational mechanisms: a set of lexical entries that are (associatively) stored in memory, and a set of symbolic rule-like operations that form larger linguistic expressions from items in the lexicon (see Pinker 1999, Clahsen 1999, Ullman 2001 for general reviews). Most of the psycholinguistic evidence for this model comes from inflectional phenomena. This raises the question of whether the distinction between two distinct representational mechanisms is specific to inflection or whether it can be extended to other morphologically complex forms, in particular to those created by derivational processes.

The answer to this question is not immediately obvious. One possibility is that the Dual Mechanism Model might only be relevant to inflection. It might be argued that in contrast to regular inflection, derivations are neither productive nor predictable, and hence combinatorial operations, are restricted to inflectional formations. This possibility can be dismissed, however, on linguistic grounds, given that derivation may in fact be just as productive as inflection. The formation of deverbal nominals in English provides a clear illustration. Just as the class of plurals in English contains a productive subclass in $-s$ and a variety of frozen patterns, derived nominals can be divided into productive formations in -ing and a range of frozen formations in $-a l$, -ion, etc. The formation of derived agentive nominals in $-e r$ is likewise highly productive, and applies to virtually any verb in English. Patterns of this type lead Anderson to conclude, in our view correctly, that '[a] high degree of productivity does not seem to be either a necessary or sufficient criterion for calling a morphological category "inflectional”'(Anderson 1992:78).

The second possibility is that what should matter to the Dual Mechanism Model is not 
inflection per se, but rather the postulation of different mental representations for combinatorial operations and lexical entries (see Pinker 1999: 237). This alternative establishes a general opposition between items that are stored in the lexicon and elements that are defined from lexical items by rule-like operations, and hence predicts that productively defined inflected and derived forms should pattern together, contrasting uniformly with irregular formations (see also Ullman 2001: 719).

The third possibility is that inflectional and derivational processes differ in respects that bear on the contrast between built (i.e. rule-based) and stored items. The treatment of inflection and derivation in realization-based models of morphology (Anderson 1992, Stump 2001) implies a difference of precisely this sort. Whereas productive derivation is modeled by rules that define new entries, productive inflection is expressed by rules of exponence that map grammatical properties onto simple forms. Consequently, the output of an inflectional rule is a form, not an entry (i.e., a feature-form pairing). Construed as a claim about the mental grammar, this contrast predicts differences between the way that inflected and derived forms are represented and processed by the speaker/hearer, since productively defined derived forms - like irregular forms and unlike regularly inflected forms — are associated with entries.

From a linguistic perspective, both the second and the third hypotheses are equally plausible, but we will argue that the experimental results reported below provide a basis for deciding between these two alternatives. Our studies indicate that productively defined derived and regularly inflected forms fully prime the stems from which they are defined, and this is compatible with both hypotheses. However, we also found that productively defined derivational forms produce full-form frequency effects in unprimed lexical decision, like irregular forms and unlike regularly inflected 
forms. These results will be interpreted as support for the claim that inflection differs systematically from derivation in that productively derived forms are listed in stem entries whereas regularly inflected forms are not listed in the mental lexicon. Consequently, we suggest a refinement of the Dual Mechanism Model that distinguishes three types of elements: (i) frozen irregular forms, stored in entries, (ii) productively derived stem entries and (iii) productively inflected word forms which are not represented in lexical entries.

\section{Previous studies}

Although a detailed review of previous psycholinguistic studies of derivational morphology is beyond the scope of the present article (see, e.g., McQueen \& Cutler 1998 for one summary), it is important to try to place the present study in the context of previous research.

Studies examining subjects' acceptability ratings for derivational forms in English (Alegre \& Gordon 1999) and Japanese (Hagiwara et al. 1999) suggest that the contrast between built and stored forms posited in the Dual Mechanism Model does not only hold for inflection but also for derivational morphology. Alegre \& Gordon (1999) found that subjects' acceptability ratings for novel derived forms with so-called non-neutral affixes such as -ion and -al revealed similarity effects, i.e., nonce forms that resembled existing derived forms produced higher acceptability scores than nonce forms that were dissimilar to existing ones, indicating that non-neutral derived forms are stored in associative memory. Novel forms with so-called neutral affixes such as -ness and -er, on the other hand, did not yield similarity effects, suggesting that such forms are rule-based. Hagiwara et al. (1999) obtained acceptability ratings from native speakers of Japanese (normal adults controls and aphasic patients) on 
deadjectival nouns with the suffixes $-s a$ or $-m i$. They found that $-s a$ derivations produced rating patterns similar to those obtained for regular inflection, whereas $-m i$ derivations patterned together with irregular inflection. Corresponding dissociations were found among the aphasic patients. For example, Broca's aphasics were impaired in their ratings on $-s a$ forms, but not on $-m i$ forms. Hagiwara et al. interpret these contrasts to mean that $-s a$ derivations are based on a combinatorial rule while $-m i$ forms are stored in associative memory; see also Sugioka et al. (2001) for causative formation in Japanese.

With respect to language production, Garrett (1980) found that in speech error corpora so-called stranding errors mostly involve stems and inflectional morphemes, while such errors were rare in derived forms. More recently, Janssen (1999), using an implicit priming paradigm in which participants had to produce words from a restricted set of alternatives, found that a regularly inflected word form led to a preparation effect for the production of related words whereas a corresponding derived form produced no such effect under the same circumstances. These results indicate differences between regular inflection and derivation and, as Janssen argued, are compatible with accounts that maintain the linguistic contrast between inflection and derivation.

There are also several comprehension studies comparing inflection and derivation. The results are, however, not entirely conclusive. There is evidence from different languages that supports the linguistic contrast between inflection and derivation. For example, Stanners et al. (1979) found that derivational forms produced smaller priming effects towards corresponding stem forms than regularly inflected primes. Similarly, Friederici et al. (1989) observed priming effects between word pairs containing regularly inflected German adjectives (rein-es - rein-e 'pure') but not for 
corresponding pairs containing derivational forms (rein-lich 'cleanly' - Rein-heit 'pureness'). Feldman (1994) obtained similar results for Serbian: inflectionally related primes produced significantly stronger priming effects towards their corresponding stems than derivationally related primes. For Italian, Burani \& Laudanna (1992) report processing differences between derived and inflected forms for word pairs containing a target with a semantically different, but homographic root. Whereas inflected forms (mutarano 'they changed') inhibited the recognition of the target (mute 'silent'), no such inhibition effect occurred after the presentation of derived forms (mutevole 'changeable'); see also Laudanna et al. (1992). These results have been taken to indicate that a word's morphological structure is more transparent for inflectional than for derivational forms. Using cross-modal priming, Marslen-Wilson et al. (1994) reported a complex pattern of experimental results for different kinds of derivational forms in English. Strong priming effects were found between semantically transparent derived forms (punishment) and their stems (punish), but not between pairs of semantically opaque forms (casualty - casual). Marslen-Wilson et al. argue that semantically transparent derivational forms have decomposed lexical representations (e.g. punish+ment) thereby making the unmarked stem (punish) available for priming. Results from (unprimed) lexical decision tasks also suggest that inflected and derived forms are processed differently; see e.g. Bertram et al. (1999) for Finnish and Bertram et al. (2000) for Dutch.

Other experimental studies failed to find differences between the processing of derivational and inflectional forms. Fowler et al. (1985), for example, obtained full priming for inflected as well as for derived forms. In a more recent study, Raveh \& Rueckl (2000) also report that regularly inflected and derived forms produced equivalent levels of priming. Note, however, that Fowler et al. (1985) did not control 
for frequency and semantic transparency. Raveh \& Rueckl (2000) lumped together different affixes into their experimental conditions; the inflectional condition included forms ending in $-e d$, $-i n g$, and $-s$, and the derived one forms ending in -er, -age, $-a r,-y,-o r,-i v e,-u r e$, and -ful. Note, however, that the results of Bertram et al. (1999, 2000) indicate processing differences between different affixes. For example, inflected words with unambiguous affixes are more likely to be decomposed than inflected words with ambiguous affixes. This factor was not controlled in Raveh \& Rueckl's study, and this may have affected the results. Note also that their experiment 2 produced a clear contrast between derivational and inflectional forms: whereas the inflected primes did not significantly differ from the identity primes, yielding a full priming effect, the derivational forms were significantly less efficient primes, yielding a reduced priming effect (see Raveh \& Rueckl 2000: 110). This result is compatible with those from other studies in which processing differences between inflected and derivational forms were found.

\section{The present study}

To further illuminate the contrasts between derived and inflected forms and probe the mental representation of derived forms, we have investigated a set of derivational suffixes of German in unprimed visual lexical decision tasks and cross-modal immediate repetition priming tasks. In what follows, we will first discuss linguistic aspects of derived forms in German. We will then report two main experiments on derived forms. Finally, the results will be compared with results from corresponding experiments on inflected word forms. The results, we will argue, are in line with the linguistic contrast between inflection and derivation and indicate that the mental representations of productively derived forms are systematically different from those 
of inflected forms.

\section{Linguistic aspects of derived stems with specific reference to German}

Traditional linguistic descriptions of morphological systems often assume that derivational or lexeme formation processes are distinct from, and in some sense prior to, inflectional or paradigmatic processes (see Spencer 1991 for review). We can illustrate the differences that underpin this contrast by comparing the distribution of the derived forms in (1b) and (1c) with the inflected forms in (1d) and (1e).
a. les- 'read'
b. les-bar, 'readable', Les-er 'reader'
c. un-lesbar 'unreadable', Leser-brief 'letter to the editor'
d. unlesbar-e 'unreadable-nom.pl', Leserbrief-e 'letters to the editor'
e. las-t 'read-2pl past indicative', läse-st 'read-2sg subjunctive'

The verb root les- in (1a) may participate in lexeme formation processes, including the productive category-changing rules that derive the deverbal adjective lesbar and the deverbal noun Leser in (1b). As the examples in (1c) show, these forms may in turn participate in subsequent lexeme formation and compounding. In addition, these derived outputs may provide the input to applicable inflectional rules, as the agreeing adjective unlesbare and the plural compound Leserbriefe in (1d) indicate. The forms in (1e), in contrast, are fully inflected words, marked by regular $2 \mathrm{pl}$ and $2 \mathrm{sg}$ agreement suffixes. Neither the inflected words as a whole, last or läsest, nor their inflectional bases, las- or läse-, may occur in any derivational formations. Precisely the same restriction applies to the inflected forms of the derived nouns and adjectives 
in (1d). These basic distributional differences illustrate the traditional view that derivation creates new lexemes that may participate in derivation or inflection, whereas inflection creates forms that are excluded from derivation. The corresponding contrast between regular inflectional and derivational processes likewise reflects their role within a morphological system; specifically the fact that derivation may feed either derivation or inflection, while inflection bleeds derivation.

It should be acknowledged that other criteria are sometimes invoked to distinguish derivation from inflection. However, these criteria tend to identify properties - like productivity, discussed above - which are characteristic rather than definitional. In addition, there are various familiar patterns that are sometimes interpreted as counterevidence to the claim that inflection bleeds derivation. To accommodate these patterns, Booij (1994, 1996) distinguishes derivation-feeding 'inherent' inflection from derivation-bleeding 'contextual' inflection. Yet, the inflectional treatment of the 'inherent' class depends essentially on properties like productivity and transparency, which do not provide a reliable basis for morphological classification. Given these criteria, it is unclear, for example, why participles, which pattern in many respects like adjectives, should be regarded as inflected forms of a verb. An inflectional classification of comparative and superlative forms is also questionable in cases where, as in German, these forms - like basic adjective stems - clearly provide a base for regular agreement inflection. Indeed, one often finds that nonfinite verbs and non-absolute adjectives are classified as derivational formations in traditional accounts (see, e.g., Palmer 1974). The evidence for other categories, such as 'inherently inflected' plurals is equally equivocal. This classification is proposed to account for compounds, such as Taschenmesser 'pocket knife', which ostensibly contain a plural noun, in this case Taschen 'pockets'. However, the number-neutrality 
of many such 'plurals' (noted by a reviewer and in the Duden, p. 480) may be taken to indicate that the plural form does not in fact participate in compounding ${ }^{1}$. An alternative account according to which a second noun stem (Aronoff 1994) underlies both plurals and certain number-neutral derivation formations has been argued at more length in Blevins (2001a).

\section{Theoretical treatments of the inflection-derivation contrast}

A number of different strategies have been developed to derive the interaction of inflection, derivation, and compounding from the organization of a morphological theory. Within the theory of Lexical Phonology and Morphology (Kiparsky 1982), the Level Ordering component orders regular inflectional processes after derivation and compounding. Although Level Ordering has been subjected to a number of criticisms (see, e.g., Aronoff \& Sridhar 1988, Fabb 1988, Szpyra 1989), many subsequent accounts attempt to reformulate the descriptive observations that it encapsulates. One strategy, applied by Wiese (1996) to some of the patterns we investigate, identifies the levels in Kiparsky's model with morphological types, i.e. with roots, stems, and words. On this alternative, derivational processes produce derived stems (rather than words), whereas regular inflection operates on stems and produces inflected words. On the assumption that no rule type maps words back onto stems, inflection will invariably bleed derivation.

Realization-based models of morphology go somewhat further in dissociating inflectional and derivational rule types. For example, although Anderson (1992) recognizes a general class of Word Formation Rules, this class is effectively

1 Although we dispute the existence of 'inherently' inflected items, we fully accept Booij's central claim that the patterns in question do not in any event support the distinction between pre-syntactic derivation and post-syntactic 
partitioned into two discrete subclasses. Derivational rules 'constitute sources for lexical stems', whereas inflectional rules 'introduce inflectional material into the surface forms of words' (Anderson 1992: 184-5, emphasis added). Other realization-based approaches, such as Matthews (1991) and Stump (2001), establish a similar split between the rules that define derivational stem entries from those that define inflected word forms. The difference between the outputs of inflectional and derivational rules is what accounts for the relative ordering of derivation and inflection. Derivational rules map one stem entry, or feature-form pairing, onto another entry. This derived entry may then provide the input to subsequent derivational rules, or may provide the base for the application of inflectional rules. In contrast, inflectional rules are simple feature-form mappings that specify the form that 'realizes' or 'spells out' a particular set of features. As a consequence, regular inflectional rules do not define new entries of any kind and cannot, in principle, provide the input to derivation. The contrasting outputs of inflectional and derivational rules are important for our account of the experimental results reported below. This account hinges on the fact that productively derived forms are listed in stem entries, whereas productively inflected forms are encapsulated within the inflectional component of the grammar. The inflectional component of a realization-based model consists essentially of a set of inflectional rules, partitioned into ordered blocks. The forms defined by each rule block are passed to the next block without at any point being cached out in lexical entries. Since the same is true of the final output of an inflectional rule, a productively inflected form does not define any new entries and hence defines no new listed forms. 
One additional property of realization-based approaches is relevant to our account. Although the Dual Mechanism Model is sometimes construed in terms of an opposition between rules and entries, this is just one way of expressing the basic distinction between built and stored elements. Precisely the same contrast can be reconstructed within an expanded rule inventory that includes traditional entries as a degenerate, highly-specific, rule type, as suggested originally by Kiparsky (1982) and acknowledged by Anderson (1992:182). In effect, the familiar distinction between dynamic rules and static entries can be recast as a contrast between rules that contain variables and those that have a constant output, as proposed in Booij (2002) or Blevins (2001b). The contrast between a regular inflectional rule and a lexical item is illustrated in (2), using a simplified version of Aronoff's (1994) realization pair format.
a. $\quad<[\mathrm{V}, 3$ sg, pres, ind $], \mathrm{X}+\mathrm{s}>$
b. $\quad<[\mathrm{V}, 3 \mathrm{sg}$, pres, ind, $\mathrm{BE}]$, is $>$
c. $\quad<[\mathrm{V}, \mathrm{WALK}]$, walk $>$

The first element of each pair identifies the features to be realized, while the second element indicates the formal spell-out. The regular 3 sg rule in (2a) spells out the bracketed features by adding the exponent ' $s$ ' to the base form represented by the variable ' $X$ '. Applied to the base of the regular verb WALK in (2c), this rule defines the regular $3 \mathrm{sg}$ form walks. The pair in (2b) likewise realizes the $3 \mathrm{sg}$ present indicative features of the lexeme BE by the constant form is. The advantage of a uniform rule-based formulation is that it allows the more specific rule in (2b) to take 
priority over (2a) and (2c), thereby accounting for the blocking of regular *bes by suppletive $i s$.

A derivational item can also be introduced by a constant realization rule, as the rule for refusal in (3a) shows. However, a derivational rule represents a mapping from one realization pair to another. For example, (3b) derives the rule for a productive deverbal nominal in -ing from the rule for the corresponding verb stem.

$$
\begin{aligned}
& \text { a. } \quad<[\mathrm{N}, \mathrm{sg}], \text { refusal }> \\
& \text { b. } \quad<[\mathrm{V}, \mathrm{LEX}], \mathrm{X}>\rightarrow<[\mathrm{N}, \mathrm{LEX}+\mathrm{ING}], \mathrm{X}+\mathrm{ing}>^{2}
\end{aligned}
$$

Thus, all derived forms share with irregular inflected forms the fact that they are stems available for further word-formation processes. This is not the case for regular inflection. On the other hand, fully productive derived stems are based on the same kinds of realization rules as fully regular inflections, namely on rules that contain variables rather than constants in their outputs (compare (2a) and (3b) vs. (2b) and (3a)). We would expect these linguistic properties of derived forms to be reflected in corresponding experimental effects.

We have examined three fully productive and semantically transparent derivational processes, marked by the suffixes -ung, -chen and -lein. Schematic derivational rules are given in (4). The nominalization rule in (4a) is cognate with the English rule in (3b). The rules in (4b) and (4c) both define diminutives, which are distinguished morphosyntactically by the diacritic property DIM in the output rules. Both rules also

2 The schematic rule in (3b) abstracts away from inessential issues involving the choice of verb roots or the semantic effect of nominalization. Since this is normally regarded as a lexeme-creating operation, the output has a new lexeme index, which is represented informally here by concatenating ING to the lexeme 
umlaut an umlautable input stem, marked by ' $\mathrm{u}(\mathrm{X})$ ', and add the suffixes -chen and -lein.

$$
\begin{array}{ll}
\text { a. } & <\text { [V, LEX }], X><[\mathrm{N}, \text { LEX+UNG }], \mathrm{X}+\mathrm{UNG}> \\
\text { b. } & <[\mathrm{N}, \mathrm{LEX}], \mathrm{X}>\rightarrow<[\mathrm{N}, \text { DIM, LEX+CHEN }], \mathrm{u}(\mathrm{X})+\text { chen }> \\
\text { c. } & <[\mathrm{N}, \text { LEX }], \mathrm{X}>\rightarrow<[\mathrm{N}, \text { DIM, LEX+LEIN }], \mathrm{u}(\mathrm{X})+\text { lein }>
\end{array}
$$

These rules (which are again deliberately schematic to abstract away from irrelevant choices) highlight two critical properties of derived nominals and diminutives, firstly, that these elements are defined by productive operations, and secondly, that they are associated with derived stem entries.

\section{Cross-modal priming of derived forms}

One possible means of experimentally investigating the lexical representations of morphologically complex word forms is via repetition priming tasks in which the semantic, phonological and/or morphological relations between pairs of primes and targets are manipulated. Previous studies have shown that the recognition of a target word is facilitated if a morphologically related prime is presented before the occurrence of the target (see, e.g., Stanners et al. 1979). This effect has been explained in terms of repeated activation of the corresponding lexical entry. Specifically, the lexical information of the prime is said to facilitate the recognition of the target, since the corresponding entry has already been activated by the prime. The technique we used is cross-modal immediate repetition priming in which subjects hear a spoken prime immediately followed by a visually presented target form for 
which they are required to make a word/non-word decision. It has been argued that cross-modal priming is particularly sensitive to modality-independent lexical representations, since any priming effects obtained from this task will have to be mediated through such representations, rather than through modality-specific overlap between prime and target at lower levels (see Marslen-Wilson et al. 1994: 6). Regularly inflected forms have been found to produce full priming effects in the cross-modal priming task, see e.g. Sonnenstuhl et al. (1999). Full priming means that a morphologically complex form, e.g. a regular German $-s$ plural (e.g. Waggons 'wagons') primes the corresponding uninflected stem (Waggon) as effectively as an identical prime. The full priming effect can be explained based on the shared stem entry of prime and target. We assume that regularly inflected forms are morphologically decomposed, e.g. Waggon $+s$, and that the recognition of such forms involves the activation of the stem form Waggon, in addition to the associated regular affix. In the cross-modal priming task, the same stem form also functions as the lexical entry for the item presented as a visual target. Repeated activation of the same stem entry facilitates the task, and hence the full priming effect. Irregularly inflected forms, on the other hand, produced reduced priming effects, for example, an irregular plural form such as Kinder 'children' is a less efficient prime towards the corresponding uninflected form Kind than an identity prime. This can be accounted for by assuming that irregulars are frozen undecomposed forms.

Given the linguistic contrasts between inflection and derivation pointed out presented in the previous section, we expect to find similar priming patterns for productive derivational processes as for regular inflection. This is because both processes are hypothesized to involve morphological decomposition. Hence, a derived form such as Kind + chen 'small child' involves the activation of the underived stem Kind and 
should therefore fully prime this form, in the same way in which a regular plural form primes its corresponding uninflected stem. If, however, derived stems were not decomposed, we would expect to find reduced priming towards their stems (similarly to what has been found for irregular inflected forms).

We tested these predictions in two cross-modal immediate repetition-priming experiments, one on diminutive forms and one on (deverbal) -ung nominalizations. Subjects were tested on three types of prime-target pairs in each experiment: (i) an 'Identity' condition, in which the spoken prime was the same as the visual target, (ii) a morphologically related 'Test' condition, in which the prime was a derived form of the target, and (iii) a 'Control' condition, in which the prime was neither semantically nor morphologically related to the target. The differences between conditions (i) and (ii) on the one hand and conditions (ii) and (iii) on the other provide measures of morphological priming.

\section{-ung nominalizations}

The derivational suffix - ung forms feminine nouns from verbal stems, for example Gründ-ung 'found-ation', which is derived from the stem of the verb gründ-en 'to found'. Deverbal -ung forms are fully productive and semantically transparent, that is, when a verb denotes an action, the corresponding deverbal noun in -ung describes the consequence or result of the action. Since affixation with -ung never changes the phonological features of the stem, it is considered to be a neutral affix or level II affix in terms of Lexical Phonology. Despite its category-changing function, -ung affixations (similarly to regular inflections) are built forms (see (4a)), and we would therefore predict full priming for these forms. 


\section{Materials}

We selected 30 nouns ending in -ung, derived from a verbal base, as test primes and the corresponding infinitive forms as targets. In addition, each target was presented in an identity condition, and a control condition. In the identity condition, primes and targets were identical. The items used as primes in the control condition were derived forms (15 with $-u n g$ and 15 with $-e r)$; in contrast to the test condition, they had a different verbal base from the corresponding targets. An example stimulus set is given in Tab.1.

\section{//INSERT TAB. 1 ABOUT HERE//}

Because no participant should see the same target more than once, the resulting 90 prime-target pairs were distributed over three stimulus lists in a Latin square design. The experimental items in each list and each condition were matched for (verbal base) frequency and syllable length; see appendix A for the complete lists of experimental items. In order to deter the participants from developing strategies based on expectations about likely relations between primes and targets, we added 170 unrelated word/word pairs to the stimulus list. These fillers exhibited different morphological patterns: 50 pairs included monomorphemic nouns as primes (e.g. Münze 'coin'), 30 pairs had bimorphemic derived nouns as primes (e.g. Liebling 'darling'), and in 90 cases a base verb (e.g. lauschen 'to listen') or a prefixed verb (erwachen 'to awaken') was used as a prime (45 each). Thus, the proportion of nouns and verbs as well as the proportion of derived and base words was balanced in the list of fillers and primes. The target in all conditions was either a prefixed verb (50\%) or a base verb (50\%). The list of 200 word/word pairs was supplemented with the same amount of corresponding word/pseudo-word pairs. The pseudo-verbs were constructed by exchanging two or three letters of existing verbs. Finally, in order to 
ensure that not all phonologically related pairs had real words as targets, 15 pseudo-verb targets that fully contained the prime (e.g. Ofen 'oven' - brofen) and 15 pseudo-verbs that overlapped with the prime partially (e.g. Pfennig 'penny' pfenten) were constructed. The overall experimental list contained 400 prime-target pairs, $88.5 \%$ of them unrelated. The items were presented in a pseudo-randomized order, ensuring that no undesired priming relation existed between neighboring items. Not more than four words or pseudo-words occurred in a sequence. The order of the stimuli was the same in each of the three stimulus lists.

\section{Method}

Participants: 60 students of the University of Düsseldorf were paid for their participation in the experiment (20 students in each version; 24 male and 36 female, mean age 27).

Procedure: The primes were spoken by a female native speaker of German and recorded on a digital audiotape. Each prime was compiled into an audio wav-file. At the beginning of each trial, a short attention tone $(200 \mathrm{~ms})$ preceded the presentation of a fixation mark in the center of a 17-inch computer monitor for $800 \mathrm{~ms}$. The fixation mark was followed by the auditory prime word, which was presented over headphones. Immediately at the offset of the spoken prime the visual target was presented in the same position as the preceding fixation mark in Arial 24 point with white letters on a dark background. The target stayed on the computer monitor for 350 ms. The measuring of the reaction times started with the presentation of the target. The participants reacted by pressing a green or a red button on a dual box. The green button (for a word) was always on the right side for right-handed and on the left side for left-handed participants. The next trial started after approximately 1,400 ms. The 
presentation of the stimuli and the measuring of the reaction times were controlled by the NESU software package (Baumann et al. 1993).

A detailed written instruction with some examples for prime-target pairs was given to each participant before the experiment began. The experiment itself started with a short practice phase (16 prime-target pairs), after which the participants had the opportunity to ask any remaining questions about the procedure. Two further breaks were provided during the experiment. The overall duration of the experimental session was approximately 45 minutes.

Analysis: Errors, i.e. nonword-responses to existing words and word-responses to pseudo-words, were removed before statistical analyses and extremely long or short reaction times exceeding more than 2 SDs from a participant's mean per condition were removed from the data set. Neither errors $(1.1 \%)$ nor extreme reaction times (4.5\%) showed any significant differences across conditions. For the remaining data, mean response times for each participant and each item were entered into two separate ANOVAs with the factor 'Prime Type' (Identity vs. Test vs. Control).

\section{Results}

Fig. 1 presents the mean reaction times for each condition.

\section{//INSERT FIG.1 ABOUT HERE//}

Recognition times in the identity and in the test condition were shorter than in the control condition. Moreover, in the test condition, i.e. after hearing derivational forms with -ung, recognition times on their corresponding base verbs were similar to those in the identity condition, yielding a full priming effect. These observations are confirmed by statistical analyses. The ANOVA revealed a significant main effect of 'Prime Type' for subjects $(\mathrm{F} 1(1,44)=32.40 p<.001)$ as well as for items $(\mathrm{F} 2(1,29)=$ 
62.90, $p<.001$ ). Pairwise comparisons using matched $t$-tests (see Tab.2) show that the differences between the identity condition and the control condition and between the test condition and the control condition are statistically significant for both subjects and items. There was no significant difference between the identity and the morphologically related test condition.

\section{//INSERT TAB.2 ABOUT HERE//}

The results show that -ung nominalizations prime their base verb as effectively as the base verb itself, thus yielding full priming. This finding confirms that derivational forms with -ung have decomposed lexical representations.

\section{Diminutives}

Results from cross-modal priming experiments on diminutives in German were first reported in Sonnenstuhl et al. (1999). The following presents a brief summary.

Diminutive formation is as productive and semantically transparent as -ung nominalization. However, in contrast to -ung forms, diminutive suffixation co-occurs with a stem vowel change (umlaut) wherever possible. To determine the role of these stem changes, Sonnenstuhl et al. examined diminutives with and without umlaut in separate experimental conditions. Experimental items were constructed by adding the suffix -chen (or -lein) to the nominal stem (Rad 'wheel' - Rädchen 'small wheel'; Dach 'roof' - Dächlein 'small roof'). Table 3 shows an example stimulus set.

\section{//INSERT TAB.3 ABOUT HERE//}

Table 4 presents the overall means per condition (for subjects) and pairwise statistical comparisons; the mean RTs for items were very similar to those in Tab.4, and the statistical comparisons revealed the same effects (Sonnenstuhl et al. 1999: Tab.9, p.222). 


\section{//INSERT TAB.4 ABOUT HERE//}

As shown in Tab.4, the unprimed control condition produced longer reaction times than the identity and the diminutive conditions. This was significant for diminutives with umlaut as well as for diminutives without umlaut. By contrast, the size of the priming effect in the diminutive conditions did not differ significantly from the one in the identity conditions, regardless of whether or not they had a stem vowel change. Thus, all diminutive forms produced full priming effects in this experiment.

\section{Preliminary summary}

Taken together, full priming was found for derived forms in -ung, -chen, and -lein, similar to what has been found for regularly inflected word forms, such as $-s$ plurals in German (Sonnenstuhl et al. 1999). This contrasts with irregular inflection (e.g. $-n$ participles and -er plurals) for which reduced priming was found (ibid). These findings correspond to the linguistic distinction between built and frozen forms. The productive derivational processes we studied here involve combinatorial rules and morphological decomposition, just like regularly inflected forms, and the full priming effects obtained for these forms can be explained based on the shared stem entry of prime and target (see e.g. Kind + chen $\rightarrow$ Kind, Waggon $+s \rightarrow$ Waggon). This is not the case for irregularly inflected words which are based on frozen (undecomposed) entries from which the unmarked stem/root is not directly available, yielding reduced priming.

\section{Visual lexical decision of derived stems}

We have also examined -ung nominalizations and diminutives in an (unprimed) visual lexical decision task. In unprimed lexical decision, a subject's task is to 
discriminate between existing words (that have been encountered before) and nonce words (that have never been encountered before). This means that the task is sensitive to any trace of a word left in memory. Thus, given that unprimed lexical decision encourages subjects to rely on memory, this task is likely to tap stored full-form representations (see e.g. Pinker 1999: 138f.).

The following predictions were tested. If - ung nominalizations and diminutives are derived stems with stored full-form representations, we would expect to find corresponding frequency effects in this task, i.e., reaction times for high frequency word forms should be shorter than for low frequency ones. In contrast, if the derivational forms tested do not have stored full-form representations, we should not find word-form frequency effects.

\section{Materials}

For this experiment, we selected $20-u n g$ nominalizations and 20 diminutive forms with -chen. In order to investigate word-form frequency effects, we arranged the items pairwise so that each member had a similar stem frequency but a different word-form frequency. This resulted in the four experimental conditions shown in Table 5; see appendix B for a complete list of experimental items.

\section{//INSERT Tab.5 ABOUT HERE//}

To prevent the participants from developing expectations during the experiment, 80 morphologically complex nouns (e.g. Lügner 'liar') and 120 monomorphemic nouns (e.g. Bluse 'blouse') were added to the 40 test items as word-fillers so that half of the presented words were morphologically complex and half of them were monomorphemic. This list of 240 words was further supplemented by the same amount of pseudo-words, constructed by changing two or three letters of existing 
words. The pseudo-nouns had the same morphological structure as the real nouns, i.e., 60 of them were pseudo-derivational forms with -ung (e.g. Dömterung) and 60 of them were pseudo-diminutives (e.g. Mörkchen). In order to eliminate undesired priming effects within the experimental list, the 480 stimuli were presented in a pseudo-randomized order making sure that no semantic associations existed between consecutive items and that not more than four words or pseudo-words occurred in sequence.

\section{Method}

Participants: 45 students (12 male and 33 female, mean age 25).

Procedure: Each trial consisted of the presentation of a fixation point in the middle of a 17-inch computer monitor, followed after $600 \mathrm{~ms}$ by the stimulus in the same position. The stimuli were presented in Arial 24 point with white letters on a dark background. They stayed visible on the screen for $350 \mathrm{~ms}$. The measuring of the reaction times began with the presentation of the target. The participants reacted by pressing a green button (for a word) or a red button (for a pseudo-word) on a dual box. After an intertrial time of $1,000 \mathrm{~ms}$ the next trial was initiated.

Participants read a written instruction with a detailed description of the task, and performed a short practice phase before the actual experiment started. Two further breaks were provided during the experiment. The overall duration of an experimental session was approximately 35 minutes.

Analysis: Errors, i.e. nonword-responses to existing words and word-responses to pseudo-words, were removed from the data set before further statistical analyses. The error rate was higher for low frequency derivational forms $(5.1 \%)$ than for high frequency forms $(2.2 \%)$. This difference was significant $(t(44)=3.43, p=.001$ for 
diminutives and $t(44)=3.79, p<.001$ for $-u n g$ derivations) and was consistent with the pattern of recognition times to be reported below. Extreme reaction times exceeding more than 2 SDs from a participant's mean reaction time in each condition were removed. These data $(2.2 \%)$ did not show any significant differences across conditions. The remaining data for each derivation type were entered in two separate ANOVAs for subjects and items with the factor 'Word-Form Frequency'.

Results

The mean lexical decision times are shown in Fig. 2.

\section{//INSERT Fig.2 ABOUT HERE//}

Fig. 2 shows that for both derivational forms high frequency items produced shorter lexical decision times than low frequency ones. Moreover, - ung derivations yielded overall shorter reaction times than diminutives, which is probably due to the fact that -ung forms are more frequent than diminutives; see Table 5.

Statistically, there were significant effects of 'Word-Form Frequency' in both the subject and the item analyses for diminutives $(\mathrm{F} 1(1,44)=26.30, p<.001, \mathrm{~F} 2(1,19)=$ $8.91, p=.008)$ as well as for - ung derivations $(\mathrm{F} 1(1,44)=27.23, p<.001, \mathrm{~F} 2(1,19)$ $=6.46, p=.020)$. Pairwise comparisons using matched $t$-tests confirmed these effects $(589$ vs. $548 \mathrm{~ms}, t(44)=5.13, p<.001 ; 555$ vs. $525 \mathrm{~ms}, t(44)=5.22, p<.001)$.

These results suggest that stored full-form representations are available for -ung nominalizations and -chen diminutives.

\section{Discussion}

In this section, we compare the previously reported results on derived forms with results from corresponding experiments on inflected forms. It will be shown that the 
pattern of experimental effects is compatible with the postulation of a fundamental linguistic difference between derivational and inflectional processes. Recall that according to this view, derivational morphology creates stems with stored representations whereas regular productive inflection generates inflected word forms that are not listed at any level (Anderson 1982, 1992, Perlmutter 1988, Scalise 1988, among others). Moreover, fully productive and transparent derived stems differ from irregularly inflected forms in that the former are based on rules that contain variables and are therefore analyzable into roots/stems and exponents, whereas irregulars have undecomposed representations.

\section{Comparing experimental findings on German inflection and derivation}

To see the different experimental effects between derivational and inflectional processes, Tab.6 presents a summary of the results that were obtained from (cross-modal) priming and (visual) lexical decision experiments. The first column shows the assumed representation for the test items under study. Brackets indicate which parts of an item represent stems or roots; stems may have internal structure, as for example [stift]ung] 'donation', [[kind]chen] 'small child', and [[tasche]n] 'pockets'. The second column shows whether or not cross-modal priming produced a full priming effect for the forms under study. Note that in all priming experiments derived or inflected forms such as those shown in Tab.6 were used as primes, whereas targets were forms containing the corresponding unmarked stems or roots, e.g. Waggons $\rightarrow$ Waggon 'wagon'. The third column shows whether or not the forms under study produced full-form frequency effects in (unprimed) lexical decision. Such effects were obtained in cases in which an inflected or derived form with a relatively high word-form frequency produced shorter response times than an item 
with a relatively low word-form frequency. Note that the base frequencies, i.e. the frequencies of the unmarked stem or root, were controlled in all experiments.

\section{//INSERT Tab. 6 ABOUT HERE//}

As is clear from Tab.6, regularly inflected word forms such as $-t$ participles and $-s$ plurals produced full priming and no word-form frequency effects. For irregularly inflected forms, such as $-n$ participles, $-e r$ plurals, and (irregular) $-n$ plurals the opposite pattern of results was obtained, reduced priming and full-form frequency effects. These results correspond to the linguistic representations shown in Tab. 6 for these kinds of items. Irregular participles and noun plurals are stored, undecomposed stems, hence the full-form frequency effect. They can only indirectly access their corresponding unmarked base and therefore produce reduced priming effects. Regular participles and noun plurals, on the other hand, do not have stored word-form representations, and hence the lack of a full-form frequency effect. Instead, they are decomposable into an unmarked stem/root plus the regular affix, and given this representation they can fully prime their corresponding base stem or root.

As can be seen from Tab.6, the derivational forms tested in the present study yielded a pattern of experimental effects that differs from both the one for regular inflection and the one for irregulars. However, like in the case of the inflected words, the experimental effects obtained for derived forms correspond to their linguistic representations, illustrated in Tab.6. The derived forms share with the irregulars the fact that their full forms represent stems, and hence the full-form frequency effects in the lexical decision task. Moreover, their internal structure is parallel to regularly inflected $-t$ participles and $-s$ plural forms in that $-u n g$ nominalizations, $-c h e n$ and -lein diminutives are built forms, as for example in kind+chen. We assume that the recognition of such forms involves the activation of the underived stem form (e.g. 
kind), in addition to the associated derivational suffix. Thus the full priming effect obtained for such forms can be explained based on the shared stem entry of prime and target.

\section{German -n plurals}

Consider, in the light of the account given for derived forms, the experimental results from Sonnenstuhl and Huth (2002) on $-n$ plurals in German. Note that $-n$ plurals do not represent a homogeneous class in German. There are (at least) two types, with different degrees of productivity and predictability. While plural formation with $-n$ is fully predictable for feminine nouns with a stem-final Schwa, e.g. (die) Tasche Taschen 'the pocket - pockets', plural formation with $-n$ is not predictable for non-feminine nouns without a stem-final Schwa, e.g. der Bauer - Bauern 'the farmer - farmers'. In Tab.6, the latter are labelled class $I I-n$ plurals and the former class $I-n$ plurals. Given the fact that there is no single exception to $-n$ plurals of class I, i.e., all feminine nouns with a stem-final Schwa take the $-n$ plural, we might hypothesize that class I $-n$ plurals are rule-based, i.e., constitute built forms, whereas all other $-n$ plurals are irregular, i.e., stored forms. On the other hand, however, all kinds of $-n$ plurals (irrespective of their gender or stem properties) are in principle available for further word-formation processes yielding forms such as taschen-los 'pocket-less', or Bauern-schaft 'farming community'. Thus, class I $-n$ plurals such as Tasche - Taschen differ from regular $-s$ plurals in that $-n$ plurals may feed further lexeme formation, whereas $-s$ plurals never do; compare taschen-los with *autos-los 'car-less'. These properties are reflected in the representations posited for the two types of $-n$ plurals in Tab.6, according to which all $-n$ plurals are stems and in which 
$-n$ plurals of class I (but not of class II) are built forms yielding internally structured root + affix representations. The experimental results on class II $-n$ plurals obtained by Sonnenstuhl \& Huth (2002) correspond to their linguistic representation. Class I $-n$ plurals form stems, hence the full-form frequency effect in the lexical decision task. On the other hand, these $-n$ plurals are rule-based and decomposable, hence the full priming effect found in the cross-modal priming task.

\section{Alternative accounts}

Finally, we will briefly discuss how previous psycholinguistic accounts of the similarities and differences between inflection and derivation might explain the results summarized in Tab.6. Consider first Raveh \& Rueckl's (2000) proposal that the processing of derivation and inflection is not fundamentally different and that factors other than their linguistic representation (e.g. statistical variables, orthographic and visual properties of the items involved) should determine how they are processed. This account is not supported by our findings. If, for example, orthographic similarity determines morphological priming, one would expect that the plural form kinder 'children' primes kind more efficiently than the diminutive kindchen. Yet, we found the opposite pattern, full priming for diminutives and reduced priming for (irregular) plurals. Another example comes from $-s$ versus - er plurals, which are 'statistically' similar, in that both plural forms with $-s$ and with $-e r$ have low (type) frequencies in the German language; see Sonnenstuhl (2001: 106) for relevant frequency counts. Yet, in our experiments they behaved very differently; see Sonnenstuhl et al. (1999) for further discussion.

Another suggestion comes from Laudanna et al. (1992) who argued for a stem representation hypothesis, according to which (regularly) inflected words have lexical 
representations that are decomposed into stems plus inflectional affixes, whereas derivational forms are not decomposed into roots plus derivational affixes. Our finding that both productive derivation and regular inflection (but not irregular inflection) produce full priming effects in the cross-modal priming task, whereas irregular inflection does not, challenges this hypothesis.

A third proposal comes from several proponents of the Dual Mechanism Model (Alegre \& Gordon 1999, Pinker 1999, Hagiwara et al. 1999, Sugioka et al. 2001, Ullman 2001) who argued for a general opposition between combinatorial operations and lexical lookup which should apply to both inflectional and derivational morphology. It is predicted here that productively defined inflected and derived forms should produce the same experimental effects which should uniformly contrast with irregular formations, since they are both based on combinatorial operations. Our findings provide only partial support for these predictions. Tab.6 shows that the priming results are indeed parallel for the derivational and the regularly inflected forms we tested, and that they contrast with the results on irregular inflection in that only the former yielded full priming effects. These results are compatible with the view that both (productive) derivation and (regular) inflection involve combinatorial rules. In unprimed lexical decision, however, we found that the same derivational forms produce full-form frequency effects and hence pattern with irregular forms and unlike regularly inflected forms. The idea of a general opposition between combinatorial operations and stored forms does not explain why (productive) derivational forms pattern differently from both regular and irregular inflection. 


\section{Conclusion}

Investigating fully transparent and productive derivational forms with the suffixes -ung, -lein, and -chen, we found that in cross-modal priming tasks these forms were effective primes of corresponding underived forms. We argue that these effects correspond to the lexical representations of these items, i.e., derived forms with -ung, -lein, and -chen are built (rule-based) forms from which the base stems are directly available for priming. In unprimed lexical decision, on the other hand, we found that diminutives and -ung nominalizations produced full-form frequency effects. We argue that these effects reflect the fact that derived forms are stems with stored full-form representations that are picked up by the lexical decision task.

To account for these findings, we suggest a refinement of the Dual Mechanism Model that treats productive inflection and derivation both as the result of combinatorial operations but associates productive derivation (like irregularly inflected items) with stored entries. This interpretation of our experimental results is compatible with models of morphology that distinguish inflection from derivation and particularly with realization-based models of morphology that express this split in terms of a contrast between entry-defining derivation and form-defining inflection. We conclude that the refined Dual Mechanism Model provides the best account for our experimental findings; alternative accounts of the derivation/inflection contrast were found to be less successful. 
Acknowledgements

The research reported in this paper is supported by a German Research Council grant (SFB 282/C7) to HC. We thank Meike Hadler, Rebecca Groß, Peter Prüfert, and Axel Huth for assistance in administering the experiments. We are also grateful to the ESRC Research Seminar series on 'Models and Methods in Morphology' that stimulated this collaboration. Acknowledgements for helpful comments are due to Harald Baayen, Iris Berent, Geert Booij, Andrew Carstairs-McCarty, Grev Corbett, Wolfgang Dressler, Sonja Eisenbeiss, Jen Hay, Andrew Spencer, Greg Stump, Michael Ullman, Richard Wiese and Dieter Wunderlich. 


\section{References}

Alegre, M. and Gordon, P. 1999. Rule-based versus associative processes in derivational morphology. Brain \& Language 68, 347-354.

Anderson, S. R. 1982. Where's morphology? Linguistic Inquiry 13, 571-612.

Anderson, S. R. 1992. A-morphous morphology. Cambridge: CUP.

Aronoff, M. 1994. Morphology by itself. Cambridge, MA: MIT Press.

Aronoff, M. and Sridhar, S. N. 1988. Prefixation in Kannada. In M. Hammond and N. Noonan (eds.), Theoretical morphology (pp.179-191). San Diego, Academic Press.

Baayen, H., Piepenbrock, R., and van Rijn, G. 1993. The CELEX lexical database (CD ROM). Philadelphia, PE: Linguistic Data Consortium, University of Pennsylvania.

Baumann, H., Nagengast, J., and Klaas, G. 1993. New experimental setup (NESU). Ms. Nijmegen: Max-Planck-Institute for Psycholinguistics.

Bertram, R., Baayen, H., and Schreuder, R. 1999. Effects of family size for complex words. Journal of Memory and Language 42, 390-405.

Bertram, R., Schreuder, R., and Baayen, H. 2000. The balance of storage and computation in morphological processing: the role of word formation type, affixal homonymy, and productivity. Journal of Experimental Psychology: Memory, Learning, and Cognition 26, 419-511

Blevins, J. P. 2001a. Paradigmatic derivation. Transactions of the Philological Society 99(2), 211-222.

Blevins, J. P. 2001b. Stems and paradigms. Ms. RCEAL: University of Cambridge.

Booij, G. 1994. Against split morphology. In G. Booij and J. van Marle (eds.), Yearbook of Morphology 1993, 27-49. 
Booij, G. 1996. Inherent verses contextual inflection and the split morphology hypothesis. In G. Booij and J. van Marle (eds.), Yearbook of Morphology 1995, 116.

Booij, G. 2002. The morphology of Dutch. Oxford University Press: Oxford.

Burani, C., and Laudanna, A. (1992). Units of representation for derived words in the lexicon. In R. Frost and L. Katz (eds.), Orthography, Phonology, Morphology, and Meaning. Amsterdam: North-Holland (pp. 361-376)

Clahsen, H. 1999. Lexical entries and rules of language: A multi-disciplinary study of German inflection. Behavioral and Brain Sciences 22, 991-1060.

Clahsen, H., Eisenbeiss, S. \& Sonnenstuhl, I. (1997) Morphological structure and the processing of inflected words. Theoretical Linguistics 23, 201-249.

Fabb, N. 1988. English suffixation is constrained only by selectional restrictions. Natural Language and Linguistic Theory 6, 527-539.

Feldman, L. B. 1994. Beyond orthography and phonology: Differences between inflections and derivations. Journal of Memory and Language 33, 442-470.

Fowler, C. A., Napps, S. E., and Feldman, L. B. 1985. Relations among regular and irregular morphologically related words in the lexicon as revealed by repetition priming. Memory and Cognition 13, 241-255

Friederici, A. D., Schriefers, H. J., and Graetz, P. A. M. 1989. Abruf und Repräsentation morphologisch komplexer Wörter verschiedener Wortklassen. In H. Günther (ed.), Experimentelle Studien zur Flexionsmorphologie (pp. 41-70), Hamburg: Buske

Garrett, M. F. 1980. Levels of processing in sentence production. In B. Butterworth (ed.), Language production. Vol. 1 (pp.177-220). London: Academic Press.

Hagiwara, H., Sugioka, Y, Ito, T., Kawamura, M. and Shiota, J. 1999. Neurolinguistic 
evidence for rule-based nominal suffixation. Language 75, 739-763.

Janssen, D. 1999. Producing past and plural inflections. Dissertation. Nijmegen: Max-Planck-Institute for Psycholinguistics.

Kiparsky, P. 1982. From cyclic phonology to lexical phonology. In H. van der Hulst and N. Smith (eds.), The structure of phonological representations. Part 1 (pp.131-175). Dordrecht: Foris.

Laudanna, A., Caamazza, A., and Badecker, W. 1992. Processing inflectional and derivational morphology. Journal of Memory and Language 31, 333-348

Marslen-Wilson, W., Tyler, L., Waksler, R., and Older, L. 1994. Morphology and meaning in the English mental lexicon. Psychological Review 101, 3-33.

Matthews, P. 1991. Morphology. Cambridge: Cambridge University Press.

McQueen, J. M. and Cutler, A. 1998. Morphology in word recognition. In A. Spencer and A. M. Zwicky (eds.), The handbook of morphology (pp.406-427). Oxford: Blackwell.

Palmer, F. R. 1974. The English verb. London: Longman.

Perlmutter, D. M. 1988. The split morphology hypothesis. In M. Hammond and N. Noonan (eds.), Theoretical morphology (pp.79-100). San Diego, CA: Academic Press.

Pinker, S. 1999. Words and rules: The ingredients of language. New York: Basic Books.

Raveh, M., and Rueckl, J. G. 2000. Equivalent effects of inflected and derived primes: Long-term morphological priming in fragment completion and lexical decision. Journal of Memory and Language 42, 103-119

Scalise, S. 1988. Inflection and derivation. Linguistics 26, 561-581.

Sonnenstuhl, I. 2001. Deutsche Plurale im mentalen Lexikon: Experimentelle 
Untersuchungen zum Verhältnis von Speicherung und Dekomposition. Unpublished PhD. dissertation: University of Düsseldorf.

Sonnenstuhl, I. and Huth, A. 2002. Processing and representation of German $-n$ plurals: A dual mechanism approach. To appear in Brain and Language.

Sonnenstuhl, I., Eisenbeiss, S., and Clahsen, H. 1999. Morphological priming in the German mental lexicon. Cognition 72, 203-236.

Spencer, A. 1991. Morphological theory. An introduction to word structure in Generative Grammar. Blackwell: Oxford.

Stanners, R., Neiser, J., Hernon, W., and Hall, R. 1979. Memory representation for morphologically related words. Journal of Verbal Learning and Verbal Behavior $18,399-412$.

Stump, G. T. 2001. Inflectional morphology: A theory of paradigm structure. Cambridge: Cambridge University Press.

Sugioka, Y., Ito, T. and Hagiwara, H. (2001). Computation vs. memory in Japanese causative formation: evidence from agrammatic aphasics. Cognitive Studies 8 (1): $37-62$.

Szpyra, J. 1989. The phonology-morphology interface. Cycles, levels, and words. London: Routledge.

Ullman, M. 2001. A neurocognitive perspective on language: the declarative/procedural model. Nature Reviews Neuroscience 2, 717-727.

Wiese, R. 1996. The phonology of German. Oxford: Oxford University Press. 


\section{Appendix}

\section{A. Cross-modal priming: - ung nominalizations}

The following three lists present the prime-target pairs used in the test condition of this experiment. CELEX (Baayen et al. 1993) word frequencies of the items used as visual targets in the experiment are shown in brackets.

\section{List 1: mean target frequency 299}

Lackierung 'varnish'- lackieren 'to varnish' (0); Heizung 'heating' - heizen 'to heat' (34); Dichtung 'poetry' - dichten 'to write poetry' (53); Bremsung 'braking' bremsen 'to brake' (83); Lenkung 'steering system' - lenken 'to steer' (212); Sammlung 'collection' - sammeln 'to collect' (291); Verfolgung 'pursuit'- verfolgen 'to pursue' (469); Entdeckung 'discovery'- entdecken 'to discover' (472); Hebung 'lifting' - heben ‘to lift' (685); Teilung 'division' - teilen ‘to divide' (687)

\section{List 2: mean target frequency 298}

Fahndung 'search' - fahnden 'to search for' (13); Pflanzung 'planting' - pflanzen 'to plant' (40); Bohrung 'drilling' - bohren 'to drill' (48); Schaltung 'circuitry'- schalten 'to switch' (66); Verwaltung 'administration' - verwalten 'to administer' (96); Gründung 'foundation' - gründen 'to found' (370); Rettung 'rescue' - retten 'to rescue' (427); Prüfung ‘examination' - prüfen ‘to examine' (460); Öffnung 'opening' - öffnen ‘to open' (617); Erzählung ‘telling' - erzählen ‘to tell’ (846)

\section{List 3: mean target frequency 298}

Lüftung 'airing' - lüften 'to air' (22); Siedlung 'settlement' - siedeln 'to settle' (28); Kassierung 'collection' - kassieren 'to collect' (48); Ernährung 'nutrition' - ernähren 'to nourish' (64); Täuschung 'deception' - täuschen 'to decieve' (101); Störung 'disturbance' - stören 'to disturb' (320); Zeichnung 'painting' - zeichnen 'to paint' (336); Nutzung 'utilization' - nutzen 'to use' (442); Zahlung 'payment' - zahlen 'to pay' (504); Lesung 'reading' - lesen 'to read' (1113) 
B. Lexical decision: diminutives and -ung nominalizations

The following lists present the items used in the experimental conditions. CELEX frequencies (Baayen et al. 1993) are shown in brackets, noun or verb stem frequencies on the left and word-form frequencies on the right.

Low frequency diminutives (mean noun stem frequency: 176, mean word-form frequency: 0,8)

Nüßchen 'little nut' (24 - 0); Mäulchen 'little mouth' (39 - 1); Kälbchen 'little calf' (43 - 1); Schwänchen 'little swan' (48 - 0); Äpfelchen 'little apple' (74 - 0); Zwiebelchen 'little onion' (77 - 0); Täfelchen 'small board' (83 - 0); Kränzchen 'little garland' (97 - 2); Schränkchen 'small cupboard' (131 - 0); Heftchen 'booklet' (140 - 0); Hüttchen 'little hut' (165 - 0); Tänzchen 'little dance' (167 - 5); Treppchen 'small stairs' (168 - 1); Späßchen 'little joke' (174 - 1); Stämmchen 'small trunk' (209 - 0); Täschchen 'small bag' (216 - 1); Kärtchen 'small card' (283 - 2); Öhrchen 'little ear' (292 - 0); Höfchen 'little yard' (474 - 0); Lichtchen 'little light' $(621-1)$

High frequency diminutives (mean noun stem frequency: 176, mean word-form frequency: 14)

Kästchen 'little box' $(9-8)$, Glöckchen 'little bell' (40 - 10); Hähnchen 'small rooster' (41 - 17); Tütchen 'small paper bag' (43 - 32); Würstchen 'small sausage' (63 - 20); Hühnchen 'little chicken' (81 - 12); Schäfchen 'lamb' (83 - 10); Bändchen 'little ribbon' (96 - 8); Köfferchen 'small suitcase' (123 - 14); Stöckchen 'little Stick' (123 - 15); Körbchen 'little basket' (129 - 14); Mäntelchen 'small coat' (157 9); Pärchen 'couple' (158 - 15); Fähnchen 'little flag' (166 - 10); Weilchen 'little while' (179 - 19); Fläschchen 'small bottle' (216 - 23); Liedchen 'little song' (289 13); Sternchen 'little star' (422 - 15); Brüderchen 'little brother' (528 - 10); Töchterchen 'little daughter' (576 - 15)

Low frequency -ung derivations (mean verb stem frequency: 245, mean word-form frequency: 35)

Peinigung 'torture' (10 - 0); Wucherung 'proliferation' (17 - 0); Programmierung 
'programming' (25 - 6); Fälschung 'forging' (25 - 6); Schulung ‘training' (28 - 49); Schlichtung 'arbitration' (33 - 14); Bohrung 'drilling' (48 - 6); Dichtung 'poetry' (53 - 204); Bewerbung 'application' (54 - 98); Erbauung 'construction' (64 - 3); Schaltung 'circuitry' (66 - 12); Schiebung 'pushing' (109 - 1); Unternehmung 'enterprise' (131 - 9); Wanderung 'hike' (164 - 28); Lesung 'reading' (415 - 46); Vertretung 'representation' (581 - 184); Kennung 'identification' (650 - 0); Nennung ‘naming' (716 - 12); Gewinnung ‘production’ (752 - 26); Schreibung ‘spelling’ (964 $-1)$

High frequency -ung derivations (mean verb stem frequency: 245, mean word-form frequency: 140)

Züchtung 'breeding' (25 - 10); Siedlung 'settlement' (28 - 88); Schöpfung 'creation' (30 - 93); Forschung 'research' (44 - 523); Streichung 'cancellation' (54 - 16); Zündung 'ignition' (64-15); Sendung ‘transmission' (85 - 278); Leugnung 'denying' (100 - 3); Mischung 'mixture' (113 - 75); Bewunderung 'admiration' (136 - 50); Überwindung 'effort' (192 - 125); Lenkung 'steering' (212 - 56); Begleitung ‘company’ (237 - 76); Vermietung 'renting' (266 - 30); Sammlung 'collection’ (291 - 106); Gründung 'foundation' (370 - 274); Prüfung 'examination' (460 - 254); Beratung 'discussion' (503 - 396); Öffnung 'opening' (617 - 39); Rechnung 'calculation' (1068 - 294) 
$\underline{\text { Tab.1: Example stimulus set }}$

\begin{tabular}{cclcc}
\hline & & Prime & Target & No. of pairs \\
\hline I & Identity & gründen ('to found') & 30 \\
II & Test & Gründung ('foundation') & gründen & 30 \\
III & Control & Wertung ('evaluation') & 30 \\
\hline
\end{tabular}


Tab. 2: Pairwise comparisons of mean reaction times (in msec)

\begin{tabular}{lll}
\hline subjects & Identity (500) vs. Control (573) & $t(44)=5.69, p<.001$ \\
& Test (503) vs. Control (573) & $t(44)=3.55, p=.001$ \\
& Identity (500) vs. Test (503) & $t(44)=.19, p=.854$ n.s. \\
\hline items & Identity (499) vs. Control (574) & $t(29)=7.93 p<.001$ \\
& Test (502) vs. Control (574) & $t(29)=8.57, p<.001$ \\
& Identity (499) vs. Test (502) & $t(29)=.26, p=.795$, n.s. \\
\hline
\end{tabular}


$\underline{\text { Tab.3: Example stimulus set - diminutives }}$

\begin{tabular}{|c|c|c|c|c|}
\hline $\begin{array}{c}\text { Diminutives } \\
\text { without Umlaut }\end{array}$ & & Primes & Target & $\begin{array}{l}\text { No. of } \\
\text { pairs }\end{array}$ \\
\hline $\mathrm{I}$ & Identity & Schirm ('umbrella') & & 30 \\
\hline II & Diminutive & Schirmchen ('small umbrella') & Schirm & 30 \\
\hline III & Control & Streusel ('crumbs') & & 30 \\
\hline $\begin{array}{l}\text { Diminutives } \\
\text { with Umlaut }\end{array}$ & & Primes & Target & $\begin{array}{l}\text { No. of } \\
\text { pairs }\end{array}$ \\
\hline IV & Identity & Haus ('house') & & 30 \\
\hline V & Diminutive & Häuschen ('small house') & Haus & 30 \\
\hline VI & Control & Boykott ('boykotting') & & 30 \\
\hline
\end{tabular}


Tab.4: Pairwise comparisons of mean reaction times (subject analysis)

Identity (492) vs. Control (527)

$t(62)=6.26 ; p<.001$

Diminutive with Umlaut (499) vs. Control (527) $\quad t(62)=4.56 ; p<.001$

Identity (523) vs. Diminutive (526)

$t(62)=1.48 ; p=.145$, n.s.

Identity (497) vs. Control (528)

$t(62)=4.86 ; p<.001$

Diminutive without Umlaut (504) vs. Control (528)

$t(62)=3.85 ; p<.001$

Identity (497) vs. Diminutive (504)

$t(62)=1.24 ; p=.219$, n.s. 
$\underline{\text { Tab.5: Example stimulus set }}$

\begin{tabular}{lccl}
\hline Condition & $\begin{array}{c}\text { Stem Frequency } \\
\text { (mean) }\end{array}$ & Word-Form & Stimulus Example \\
& 176 & 14 & Kätzchen 'small cat' \\
\hline- chen high & 176 & 0.8 & Pflänzchen 'small plant' \\
- chen low & 245 & 140 & Gründung 'foundation' \\
\hline- ung high & 245 & 35 & Fälschung 'falsification' \\
- ung low & & & \\
\hline
\end{tabular}


Tab. 6: A summary of experimental findings on German inflection and derivation

\begin{tabular}{|c|c|c|c|}
\hline Representation & $\begin{array}{c}\text { Full priming } \\
\text { effect? }\end{array}$ & $\begin{array}{l}\text { Full-form } \\
\text { frequency } \\
\text { effect? }\end{array}$ & Source \\
\hline $\begin{array}{l}-t \text { participles: } \\
\text { ge }[\text { kauf }]-\mathrm{t}\end{array}$ & yes & no & $\begin{array}{l}\text { Sonnenstuhl et al. (1999), } \\
\text { Clahsen et al. (1997) }\end{array}$ \\
\hline $\begin{array}{l}-s \text { plurals: } \\
\text { [waggon]-s }\end{array}$ & yes & no & $\begin{array}{l}\text { Sonnenstuhl et al. (1999), } \\
\text { Sonnenstuhl \& Huth (2002), } \\
\text { Clahsen et al. (1997) }\end{array}$ \\
\hline $\begin{array}{l}\text {-er plurals: } \\
\text { [kinder] }\end{array}$ & no & yes & $\begin{array}{l}\text { Sonnenstuhl et al. (1999), } \\
\text { Sonnenstuhl \& Huth (2002), } \\
\text { Clahsen et al. (1997) }\end{array}$ \\
\hline $\begin{array}{l}-n \text { participles: } \\
\text { [gelogen] }\end{array}$ & no & yes & $\begin{array}{l}\text { Sonnenstuhl et al. (1999), } \\
\text { Clahsen et al. (1997) }\end{array}$ \\
\hline $\begin{array}{l}-n \text { plurals II: } \\
\text { [bauern] }\end{array}$ & no & yes & Sonnenstuhl \& Huth (2002) \\
\hline $\begin{array}{l}\text {-ung nominalizations: } \\
{[[\text { stift }] \text { ung }]}\end{array}$ & yes & yes & this study \\
\hline $\begin{array}{l}\text { diminutives: } \\
{[[\text { kind }] \text { chen }]}\end{array}$ & yes & yes & this study \\
\hline $\begin{array}{l}-n \text { plurals } \mathrm{I}: \\
{[[\text { tasche }] \mathrm{n}]}\end{array}$ & yes & yes & Sonnenstuhl \& Huth (2002) \\
\hline
\end{tabular}


Fig. 1: Mean reaction times (subject analysis)

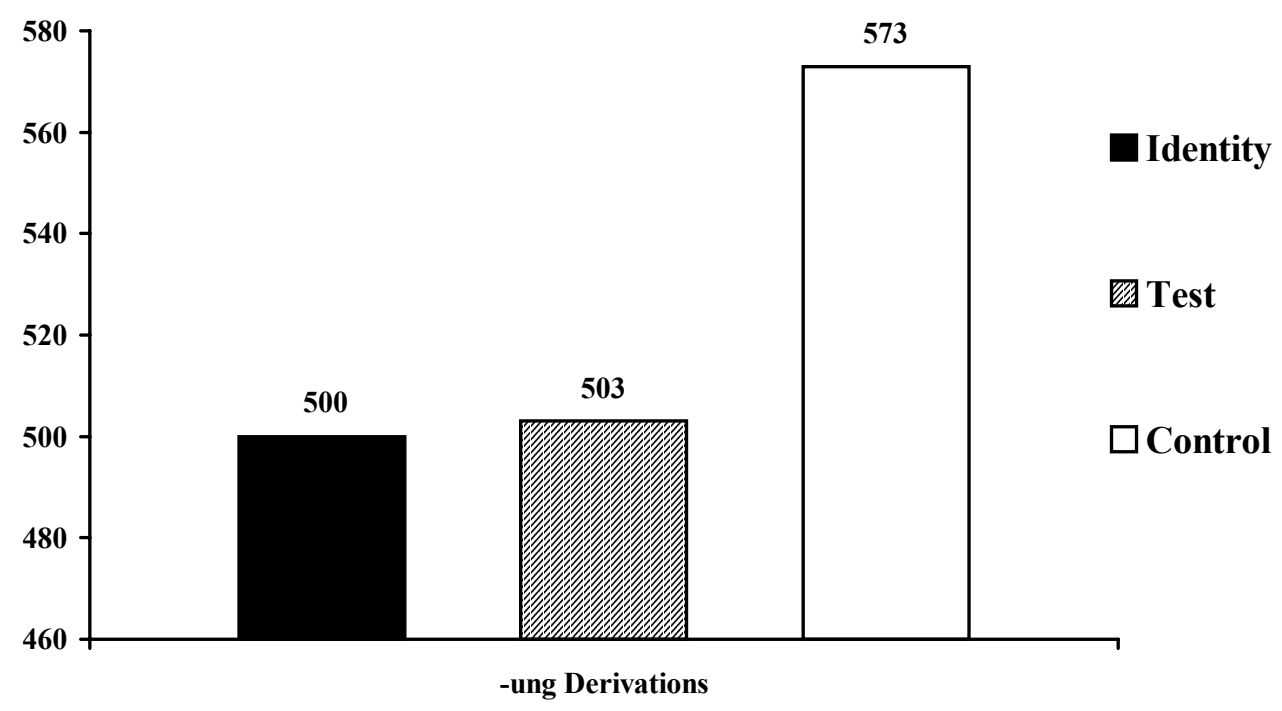


Fig.2: Mean lexical decision times to visual targets presented in isolation (subjects)

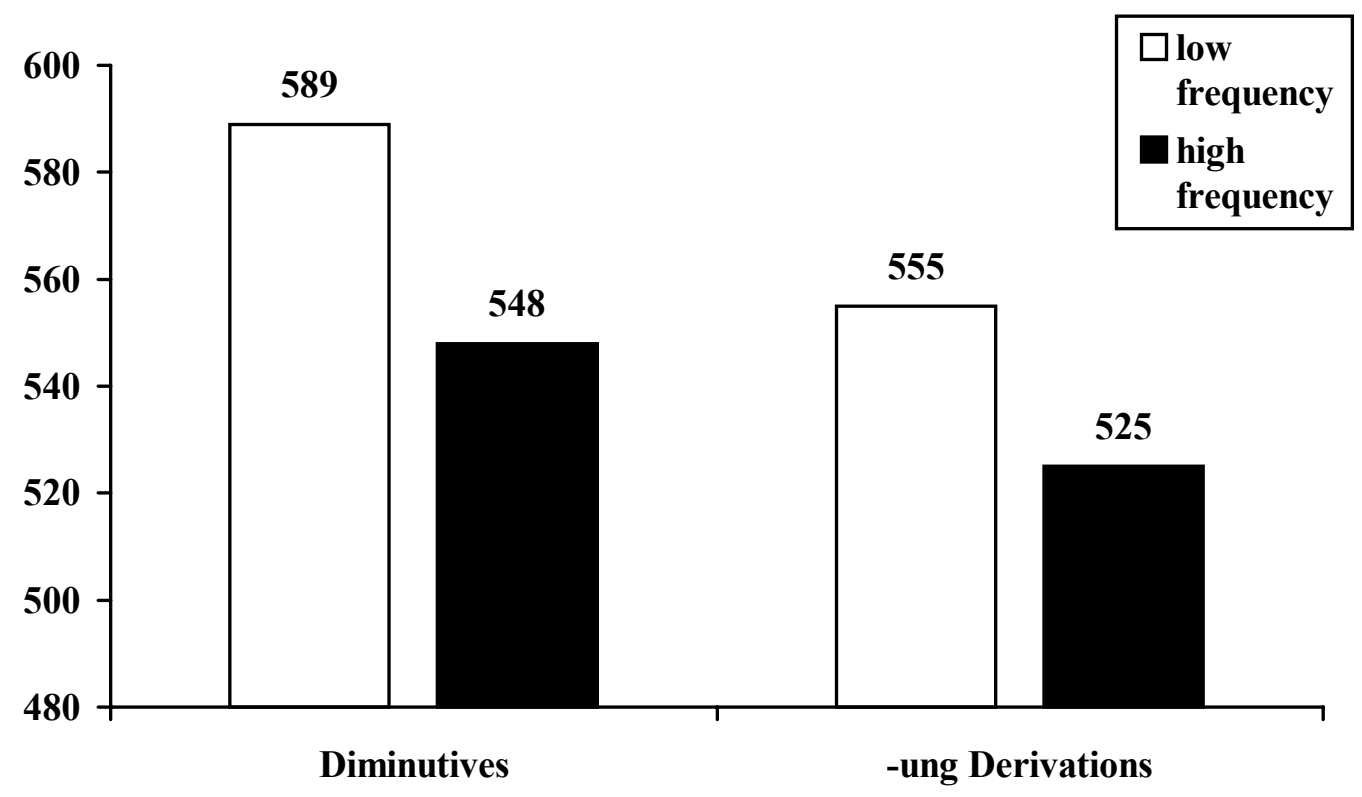

